\title{
Koronavirüs Kaygı Ölçeği’nin Türkçe Güvenirlik Ve Geçerlik Çalışması
}

\author{
Hüdanur AKKUZU1 ${ }^{1}$, Fatıma Nurefşan YUMUŞAK ${ }^{2}$, Gülşen KARAMAN ${ }^{3}$, \\ Nefise LADİKLİ ${ }^{4}$, Zeynep TÜRKKAN ${ }^{5}$, Erdi BAHADIR ${ }^{6}$
}

\begin{abstract}
Özet: Çin'in Wuhan kentinde ortaya çıkan ve kısa sürede pandemiye dönüşen yeni tip koronavirüs (COVID-19), yayılma hızı ve mortalite oranları ile diğer koronavirüs salgınlarından ayrılmaktadır. Fiziksel sağlık yanında beraberinden getirdiği travmatik yaşantılar ile psikolojik sağlık üzerinde de etkili olan COVID-19, doğrudan veya dolaylı olarak bireylerde kaygıya neden olabilmektedir. Bu çalışmada COVID-19 kaynaklı kaygıyı ölçmek için geliştirilen Koronavirüs Kayg1 Ölçeği'nin Türk örneklemindeki güvenirlik ve geçerliliğinin incelenmesi amaçlanmıştır. Çalışmaya 793'ü kadın ve 383'ü erkek olmak üzere toplam 1176 kişi katılmıştır. Katılımcılara demografik veri formu, Koronavirüs Kaygı Ölçeği, Hastane Anksiyete Depresyon Ölçeği ve Sağlık Bilişleri Anketi uygulanmıştır. Ölçeğin dil geçerliği için Türkçe’ye uygun madde çevirileri uzman görüşleri alınarak hazırlanmıştır. Yapılan açımlayıcı faktör analizi ölçeği tek faktörlü yapı sergilediğini göstermiştir. Doğrulayıcı faktör analizi sonucunda ölçeğin yapısı araştırma örneklemi için uygun bulunmuştur. Ölçek maddelerinin yüksek ayırt ediciliğe sahip olduğu görülmüştür. Test-tekrar test ve ölçüt bağıntılı güvenirlik bulguları, ölçeğin yüksek güvenirlik değerine sahip olduğunu göstermiştir. Elde edilen veriler, Koronavirüs Kayg1 Ölçeği'nin Türk örneklemi için geçerli ve güvenilir bir ölçüm aracı olarak kullanılabileceğini ortaya koymaktadır.
\end{abstract}

Anahtar Kelimeler: Covıd19, Anksiyete, Anksiyete Değerlendirme Ölçeği

\section{The Reliability and Validity Of Turkish Version Of Coronavirus Anxiety Scale}

\begin{abstract}
The new type of coronavirus (COVID-19), which occurs in Wuhan, China, and turns into a pandemic in a short time, differs from other coronavirus outbreaks in terms of spreading rate and mortality rates. COVID19 , which is also effective on psychological health with the traumatic experiences it brings along with physical health, can cause anxiety in individuals directly or indirectly. In this study, it was aimed to examine the reliability and validity of the Coronavirus Anxiety Scale, developed to measure COVID-19 induced anxiety, in the Turkish sample. A total of 1176 people, 793 females, and 383 males, participated in the study. Demographic data form, Coronavirus Anxiety Scale, Hospital Anxiety Depression Scale and Health Cognitions Questionnaire were applied to the participants. For the language validity of the scale, suitable Turkish item translations were prepared by getting expert opinions. Exploratory factor analysis showed that it has a single factor structure. As a result of confirmatory factor analysis, the structure of the scale was found suitable for the research sample. Scale items were found to have high discrimination. Test-retest and criterion-related reliability findings showed that the scale has a high-reliability value. According to the data obtained, the Coronavirus Anxiety Scale is a valid and reliable measurement tool for the Turkish sample and it is suitable to be used in future studies.
\end{abstract}

Keywords: COVID19, Anxiety, Test Anxiety Scale

${ }^{1}$ Uzm. Klnk. Psk., Fatih Sultan Mehmet Vakıf Üniversitesi, Doktora Öğrencisi, İstanbul, Orcid Id: https://orcid.org/ 00000002-8643-9684

${ }^{2}$ Uzm. Klnk. Psk., Serbest Araştırmacı, İstanbul, Orcid İd: https://orcid.org/ 0000-0002-3620-1782

${ }^{3}$ Uzm. Klnk. Psk., Fatih Sultan Mehmet Vakıf Üniversitesi, Doktora Öğrencisi, İstanbul, Orcid Id: https://orcid.org/ 00000002-9622-3713

${ }^{4}$ Ar. Gör., Fatih Sultan Mehmet Vakıf Üniversitesi, Psikoloji Bölümü, İstanbul, Orcid Id: https://orcid.org/ 0000-0002-10337251

${ }^{5}$ Uzm. Klnk. Psk., Serbest Araştırmacı, İstanbul, Orcid Id: https://orcid.org/ 0000-0002-7142-0868

${ }^{6}$ Uzm. Klnk. Psk., Gümüşhane Devlet Hastanesi, Psikiyatri Polikliniği, Gümüşhane, Orcid Id: https://orcid.org/ 0000-00028404-1779

Address of correspondence/Yazışma adresi: : Uzm. Klnk. Psk.Erdi Bahadır, Gümüşhane Devlet Hastanesi, Psikiyatri Polikliniği, Gümüşhane. E-mail: erdibhdr@gmail.com

Date of Received/Geliş Tarihi: 11.06.2020, Date of Revision/Düzeltme Tarihi: 14.07.2020, Date of Acceptance/Kabul Tarihi: 21.07 .2020

Citing/ Referans Gösterimi: Akkuzu, H., Yumuşak, F.N., Karaman, G., Ladikli, N., Türkkan Z., Bahadır, E. (2020). Koronavirüs Kaygı Ölçeği’nin Türkçe Güvenirlik ve Geçerlik Çalışması. Kıbrıs Türk Psikiyatri ve Psikoloji Dergisi, 2(2): 63-67 doi:10.35365/ctjpp.20.2.09 


\section{Giriş}

Yeni tip koronavirüs (COVID-19), özellikle solunum sistemini hedef alarak, soğuk algınlığından SARS (Severe Acute Respiratory Syndrome) ve MERS (Middle East Respiratory Syndrome) gibi şiddetli akut solunum yolu sendromlarına kadar değişen hastalıklara neden olan zoonotik koronavirüs ailesinin, mutasyon sonucu ortaya çıkan yeni bir alt türüdür (Brown ve Wang, 2020). İlk olarak 2019 Kasım ayında Cin'in Wuhan kentinde, yerleşik canlı hayvan pazarı ve epidemiyolojik olarak pazar ile bağlantılı birey ve konumlarda birincil zatürre belirtileri ile saptanan virüsün daha önce yaşanan koronavirüs salgınları ile benzer özelliklerde fakat henüz tespit edilememiş bir etiyolojiye sahip olduğu görülmüştür (Bogoch ve ark., 2020).

Virüse dair ilk araştırmalarda, diğer koronavirüs türleri içerisinde bulaş ve enfekte ediciliğinin daha yüksek, ölüm oranının ise daha düşük olduğu belirtilmiştir (Liu, Gayle, Wilder-Smith ve Rocklöv, 2020). Bir diğer araştırmada, hastalı̆̆ın ortaya çıkma süresinin 6-41 gün olduğu, ortalama 14 gün sonra ölümle sonuçlanabileceği belirtilmiş, ileri yaş grubunda olma ve zayıf bağışıklık sistemi faktörlerinin ölüm riskini arttırdığı saptanmıştır (Wang, Tang ve Wei, 2020). Virüs ile enfekte olan vakalarda en s1k görülen belirtiler ateş, öksürük, yorgunluk olurken, ek olarak balgam üretimini artmas,, baş ağrısı, soluk alıp vermede güçlük, ağızdan kan gelmesi, lenfosit düşüklüğü de semptomlar arasında bulunmaktadır (Huang ve ark., 2020; Ren ve ark., 2020).

Dünya Sağlık Örgütü, söz konusu virüsü 11 Şubat 2020 tarihinde COVID-19 olarak isimlendirmiş, virüsün 160 ülkeye yayılarak 200.000'i aşkın vaka, 8.000 ölü sayısına ulaşmasının ardından COVID-19 salgını için pandemi ilan etmiştir (Zhao ve ark., 2020). Son durumda virüs 215 ülkeye yayılmıştır ve Mayıs 2020'de dünya çapında tanı konmuş vaka sayısı 4,5 milyon, ölü sayısı ise 315 bine yükselmiştir (World Health Organization, 2020). Henüz bir tedavisi ve aşısı bulunmayan virüse karşı alınabilecek en önemli tedbirin enfekte olmamak olduğu, bunun için de kişisel hijyene özen göstermek, maske kullanmak, sosyal mesafeye uymak, temiz hava almak, dengeli beslenmek gibi tavsiyelere uyulması gerektiği vurgulanmaktadır (Guan ve ark., 2020).

Geçmiş epidemi ve pandemilerle ilgili çalışmalar, salgın süreçlerinde anksiyete, sağlık kaygısı ve güvenlikkaçınma davranışlarının yaygın olduğunu göstermektedir. Katılımcıların \%50'den fazlasının virüs kökenli salgın süreci boyunca endişe ve anksiyete taşıdığını ortaya koymaktadır (Jalloh ve ark., 2018; Lau, Griffiths, Choi ve Tsui, 2010; Main, Zhou, Ma, Luecken ve Liu, 2011; Saadatian-Elahi, Facy, del Signore ve Vanhems, 2010). COVID-19'un oluşturduğu fizyolojik tehdit ve yıkımın yanında, pandemiye dönüşmesi ile yol açtığı stres tepkisi ve hastalıkla ilintili yaşantıların kişilerde yarattığı travmatik deneyimler düşünüldügünde, salgın sürecinin ve sonrasının psikolojik bağlamda ele alınması değerli olacaktır.

Türkiye'de salgın hastalık psikolojisi ve COVID-19'un doğrudan ve dolaylı psikolojik etkilerine dair yayımlanan araştırmalar incelendiğinde, hastalık sürecinin bireylerde yarattığı tepkileri niceliksel olarak ölçebilmek için koronavirüs ile doğrudan ya da dolaylı olarak ilișkili çeşitli soruların kullanıldığı fakat Türk örnekleminde geçerlik ve güvenirlik çalışmaları tamamlanmış herhangi bir ölçüm aracının kullanılmadığı görülmektedir. Türk örneklemi için iki farklı uyarlama çalışması bulunmakla birlikte izlenen yöntemler ve metodoloji noktasında eksikliklerin bulunduğu görülmüştür (Biçer ve ark., 2020; Evren ve ark., 2020). Bu çalışma, söz konusu boşluğu gidermek ve standardize edilmiş bir ölçüm aracını Türk bilim literatürüne kazandırmak gayretiyle, koronavirüsün bireylerde yarattığı kaygıyı ölçmeye yönelik olarak geliştirilmiş Koronavirüs Kayg1 Ölçeği'nin Türkçe geçerlilik ve güvenirlik çalışmasının yapılmasını amaçlamaktadır.

\section{Yöntem}

Helsinki Deklerasyonu Prensipleri gözetilerek planlanan çalışmamız, Fatih Sultan Mehmet Vakıf Üniversitesi Etik Kurulunun 06/05/2020-6 tarih ve sayılı kararınca etik açıdan uygun bulunmuştur. Ölçek uyarlama çalışması için, ölçeği geliştiren araştırmacılardan elektronik posta yolu ile gerekli izinler alınarak çalışmalara başlanmıştır. Gerekli izinlerin sağlanmasının ardından, kesitsel-sayısal veriye hızlı biçimde erişebilmek adına bireylere yönelik ölçek uygulaması gerçekleştirilmiştir. Veri toplama araçları, mevcut pandemi koşullarında mümkün olan en geniş örnekleme ulaşabilmek amacıyla Google Forms'a yüklenerek çevrimiçi olarak yayılmıştır.

\section{Örneklem}

Yapılan çalışmaya yaş ortalaması $35,95 \pm 11,83$ olan 793'ü kadın ve 383'ü erkek olmak üzere toplam 1176 kişi katılmıştır. Katılımcıların 735'i evli iken 441'i bekardır. Maddi durumu iyi olan 494 kişi, orta olan 631 kişi ve kötü olan 51 kişi bulunmaktadır. Eğitim durumu ilkokul olan 31 kişi, ortaokul olan 62 kişi, lise olan 281 kişi, üniversite olan 614 kişi ve yüksek lisans/doktora olan 188 kişi çalışmada yer almıştır. Katılımcılar 18 yaş üstü olma kriteri gözetilerek uygun örnekleme yöntemi ile seçilmiştir. Bilgilendirilmiş onam ile çalışmaya gönüllü olarak katılmayı ve verdikleri bilgilerin bilimsel amaçlarla kullanılacağını kabul eden kişiler katılımcı olarak kabul görmüştür.

\section{Gereç}

Demografik Veri Formu: Araştırma ekibi tarafindan oluşturulan ve içerisinde katılımcıların yaş, cinsiyet, maddi durum, medeni durum, çocuk sahibi olma durumu, eğitim durumu, çalışma durumu, yaşanılan yer gibi demografik bilgilerinin sorulduğu formdur.

Koronavirüs Kaygı Ölçeği (KKÖ): Toplumsal bir kriz boyutuna erişen koronavirüs pandemisi sürecinde, hastalığın bireylerde oluşturduğu psikolojik tepkilerle bağlantılı olarak gözlenebilecek olası işlev bozucu anksiyete vakalarını ve anksiyete semptomlarının şiddetini hızlı ve güvenilir şekilde tanımlamaya yönelik olarak Lee (2020) tarafindan geliştirilmiş bir ölçektir. Beşli Likert tipi derecelendirmeye sahip 5 maddeden oluşan ölçek, çevrimiçi anket yöntemiyle erişilen 775 yetişkinden toplanan veri ile geliştirilmiştir. Analizler sonucunda \%90'lık ölçüm duyarlılığı ve \%85'lik tanı özgüllüğü hesaplanmıştır. İç tutarlık için 0,93 'lük Cronbach-Alfa değeri ile son derece güvenilir, aynı zamanda tematik ve psikometrik olarak tutarlı bir ölçüm aracı olarak kullanılabileceği ortaya konmuştur. 
Hastane Anksiyete Depresyon Ölçeği (HADÖ): Başlangıçta hastalar için olmasına rağmen toplum için de kullanılan ölçek, Zigmond ve Snaith (1983) tarafından hastalarda depresyon ve anksiyete düzeyini ve şiddetini ölçmek için geliştirilmiştir. Türkiye'de ise geçerlilik güvenilirlik çalışması Aydemir ve arkadaşları (1997) tarafından yapılmıştır. Ölçek dörtlü likert tipte 14 maddeden oluşmaktadır. Maddeler 0-3 aras1 puanlanmaktadır. Tek sayılı maddeler anksiyete düzeyini ölçerken çift sayılı maddeler ise depresyon düzeyini ölçmektedir. $1,3,5,6,8,10,11$ ve 13 . maddeler ters maddelerdir. Uyarlama çalışmasında Cronbach-Alfa değeri depresyon ölçeği için 0,78 , anksiyete ölçeği için 0,85 olarak bulunmuştur.

Sağlık Bilişleri Anketi (SBA): Hadjistavropoulos ve arkadaşları (2012) tarafından bireylerin yaşadığı sağlık anksiyetesi ile bağlantılı sağlık ile ilgili işlevsel olmayan inançlarının ölçülmesi için geliştirilmiştir. Bireylerin tıbbi tanısı alıp almamasına bağlı olarak, beşli likert tipte 20 maddelik iki ayrı formdan oluşmaktadır. 2, 4, 7, 9, 10, 15,
19 ve 20. maddeler ters kodlanmaktadır. Ölçeğin Türkçe uyarlaması Yılmaz ve Dirik (2018) tarafından yapılmıştır. Yapılan uyarlamada iç tutarlılık katsayıları tıbbi tanısı olmayanlar için 0,66-0,88 arasında; tıbbi tanısı olanlar için $0,64-0,87$ aralığındadır.

\section{Verilerin Analizi}

Verilerin analizi için açımlayıcı faktör analizi, AMOS programı (Analysis of Moment Structures) ile doğrulayıc1 faktör analizi, madde analizi, bağımsız örneklemler $\mathrm{t}$ testi ve korelasyon analizi kullanılmıştır. İstatistiksel anlamlılıkta $\mathrm{p}<.05$ kriteri göz önüne alınmıştır.

\section{Bulgular}

Uyarlama çalışmaları kapsamında öncelikle ölçeğin Türkçe çevirisi yapılarak dil geçerliliği ve yapı geçerliği incelenmiştir. Sonrasında ölçeğin Türk örnekleminde güvenirlik katsayıları hesaplanmıştır.

Tablo 1. Ölçek Maddeleri İçin Madde Analizi Bulguları

\begin{tabular}{llll}
\hline Ölçek maddeleri & Madde silindiğinde ölçek varyansı & Madde-ölçek korelasyonu & $\begin{array}{l}\text { Madde silindiğinde Cronbach Alfa } \\
\text { değeri }\end{array}$ \\
\hline Madde 1 & 3,870 & 0,529 & 0,799 \\
Madde 2 & 2,947 & 0,632 & 0,774 \\
Madde 3 & 3,527 & 0,606 & 0,777 \\
Madde 4 & 3,249 & 0,682 & 0,752 \\
Madde 5 & 3,415 & 0,597 & 0,778 \\
\hline
\end{tabular}

Tablo 2. Ölçek Maddeleri İçin Faktör Analizi Bulguları

\begin{tabular}{lll}
\hline Ölçek maddeleri & Faktör yükleri & Ortak varyans \\
\hline Madde 1 & 0,691 & 0,478 \\
Madde 2 & 0,780 & 0,608 \\
Madde 3 & 0,762 & 0,581 \\
Madde 4 & 0,813 & 0,660 \\
Madde 5 & 0,753 & 0,567 \\
\hline
\end{tabular}

Şekil 1. Doğrulayıcı Faktör Analizi Sonuçları

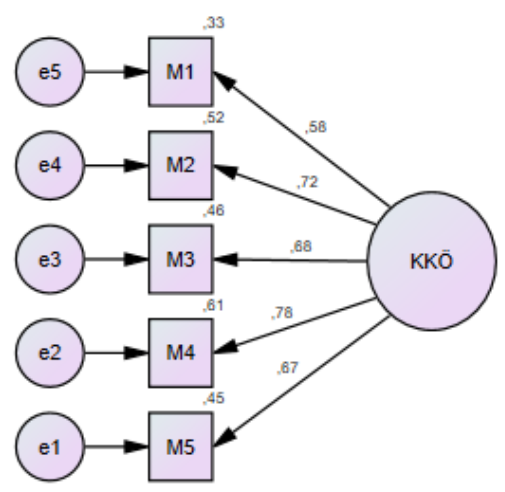

\section{Dil Geçerliliği}

Ölçeğin Türkçe'ye çevrilmesi aşamasında, İngiliz dili ve edebiyatı uzmanı ile mütercim-tercüman olan 10 kişiye İngilizce ölçek verilmiş ve en uygun Türkçe ifadeleri yazmaları istenmiştir. Toplanan veriler sonucunda en uygun Türkçe ifadeler seçilerek ölçek hazırlanmıştır. Hazırlanan Türkçe form, İngiliz dili ve edebiyatı uzmanı üç kişiye gönderilmiş ve en uygun İngilizce ifadeleri yazmaları istenmiştir. Alınan geri bildirimler sonucunda gerekli düzeltmeler yapılarak ölçeğin Türkçe formuna son hali verilmiş, hem İngiliz hem de Türk dili uzmanı sekiz kişiye 15 gün ara ile ölçeğin İngilizce aslı ve hazırlanan Türkçe formu uygulanmıştır. Yapılan analiz sonucunda iki form arasındaki korelasyonun 0,85 olduğu görülmüş ve ölçeğin Türk diline uyarlanması başarıyla gerçekleştirilmiştir.

\section{Madde Analizi}

Ölçek maddelerinin değerlendirilmesi için yapılan madde analizi sonucunda, ölçek maddeleri ile ölçek geneli 
arasındaki korelasyonun $0,53-0,68$ arasında olduğu bulunmuştur. Ayrıca madde silindiğinde elde edilen ölçek varyansı ve Cronbach Alfa değerlerinin yeterli olduğu görülmüştür (Bknz. Tablo 1).

\section{Geçerlik Bulguları}

Koronavirüs Kayg1 Ölçeği için yap1 geçerliliğinin incelenmesi için açımlayıcı faktör analizi ve doğrulayıcı faktör analizi; madde ayırt ediciliğinin analizi için bağımsız örneklemler t testi; ölçüt bağıntılı geçerliliğin tespiti için ise korelasyon analizi uygulanmıştır.

\section{Açıklayıcı Faktör Analizi (AFA)}

Yapılan açımlayıcı faktör analizinde, Kaiser-MeyerOlkin katsayısı $(\mathrm{KMO}=0,83)$ ve Bartlett Küresellik Testi veri setinin faktör analizi için uygun olduğunu göstermektedir $\quad\left(\chi^{2}(21)=1862,522 ; \quad p<0,001\right)$ Yamaç birikinti çizgesinde öz değeri 1'den büyük olan tek faktör bulunmuştur. Varimax rotasyonu ile elde edilen tek faktörlü yap1 toplam varyansın \%58'lik k1smını açıklamaktadır. Analiz sonucunda ölçek maddeleri için faktör yüklerinin $0,70-0,81$ arasında değiştiği görülmüştür (Bknz. Tablo 2). Ortak varyans değerinin 0,40 altında olmaması da düşük varyansa sahip maddenin olmadığını göstermektedir.

\section{Doğrulayıcı Faktör Analizi (DFA)}

Açımlayıcı faktör analizinde elde edilen faktör sayısının sınanması ve faktör yapısının örneklem için uygunluğunun belirlenmesi için doğrulayıcı faktör analizi yapılmıştır. Yapılan analiz sonucunda tek faktörlü yapının çalışma örneklemi için uygunluğu görülmüştür. Standardize edilmiş faktör yükleri 0,58-0,78 arasındadır (Bknz. Şekil 1). Uyum iyiliklerinin incelenmesi sonucunda faktör yapısının yüksek uyum gösterdiği bulunmuștur $\left(\chi^{2}=52,204 ; \mathrm{p}<0,001 ; \chi^{2} / \mathrm{sd}=10 ; \mathrm{GFI}=0,98\right.$; AGFI $=0,95 ; \mathrm{CFI}=0,97$; RMSEA $=0,09)$.

\section{Ayırt Edicilik Analizi}

Ölçek maddelerinin ayırt ediciliğinin incelenmesinde alınan toplam puanlar düşükten yükseğe doğru sıralanmıştır. Yapılan sıralamanın ilk \%27'lik bölümü (318 kişi) ve son \%27'lik bölümü (318 kişi) karşılaștırılmıştır. Yapılan test sonucunda Koronavirüs Kayg1 Ölçeğinden düşük puan alan ve yüksek puan alan katılımciların toplam puan ortalamaları arasında istatistiksel olarak anlamlı farklılık olduğu görülmüştür $\left(\mathrm{t}_{(634)}=-23,180 ; \mathrm{p}<0,001\right)$.

\section{Ölçüt Bağıntılı Geçerlik}

Ölçüt bağıntılı geçerliğin sınanması noktasında, Koronavirüs Kayg1 Ölçeği ile Hastane Depresyon Anksiyete Ölçeği anksiyete alt boyutu ile 0,43 'lük ve depresyon alt boyutu ile 0,38'lik korelasyon olduğu görülmüştür. Sağlı Bilişleri Anketi için korelasyon katsayıları, tıbbi tanı olma durum formu için 0,35 ve tıbbi tanı olmama durum formu için 0,39 olarak bulunmuştur.

\section{Güvenirlik}

Kovid-19 Korkusu Ölçeği'nin güvenirliğinin incelenmesinde Cronbach-Alfa iç tutarlılık katsayısı 0,81 olarak bulunmuştur. Ölçeğin iki yarısı arasındaki tutarlılığ inceleyen Guttman Split Half katsayısı 0,79 olarak hesaplanmıştır. Test-tekrar test için 120 kişi ile 15 gün ara ile yapılan uygulama sonucunda korelasyon katsayısının 0,88 olduğu görülmüştür. $\mathrm{Bu}$ noktada güvenirlik için elde edilen bulguların yeterli olduğu sonucuna ulaşılmıştır.

\section{Tartışma}

Koronavirüsün bireyler üzerindeki psikolojik etkilerinin incelenmesi için alan dizinde güvenilir ve geçerli ölçüm araçlarının olmaması ciddi bir eksiklik olarak görülmüştür. $\mathrm{Bu}$ kısımda elde edilen bulgular alan dizin çalışmaları ile tartışılmıştır.

Dil geçerliliği için uzmanlardan alınan geri dönüş sonucunda hazırlanan form Türkçe için uygun bulunmuştur. İngilizce ve Türkçe formlar arasındaki tutarlılığın yüksek olması bu uygunluğun istatistiksel olarak anlamlı olduğunu göstermiştir (Akbaş ve Korkmaz, 2007). Yap1 geçerliğinin sınanmasında elde edilen bulgular veri setinin faktör analizine uygun olduğunu ve ölçeğin tek faktörlü yapıya sahip olduğunu belirtmiștir (Güriş ve Astar, 2019; Kalayc1, 2010). Doğrulayıcı faktör analizi sonucu bulunan uyum iyiliği indeksleri alan dizin çalışmalarında kabul edilen düzeylerde bulunmuştur (Bayram, 2010). Uyum iyiliklerinin karşılanmasında anlamlı bulunan Ki-kare test istatistiği, örneklemin büyüklüğünden etkilenmesi ile açıklanabilir (Meydan ve Şeşen, 2011). Bulgular orijinal ölçek çalışması ile benzerlik göstermekte ve yap1 geçerliğinin sağlanmasına imkân sunmaktadır.

Büyüköztürk (2012) ölçek maddelerinin ayırt ediciliğinin geçerlik için bir ölçüt olduğunu belirtmiştir. Yapılan karşılaştırma analizinin anlamlı bulunması ayırt edici geçerliğin sağlandığını göstermektedir. Geçerliğin incelenmesinde son olarak yapılan ölçüt bağıntılı geçerlik incelemesinde, Koronavirüs Kayg1 Ölçeğinin benzer içerikli ölçeklerle ilişsili bulunmuştur (Ercan ve Kan, 2004). Bütün bulgular ölçeğin Türkçe geçerlik incelemelerinin alan dizin çalışmaları ile belirtilen kriterlere uygun olduğunu göstermiştir. Son olarak güvenirlik incelemeleri sonucunda orijinal ölçekte hesaplanan 0,93 'lük iç tutarlık katsayısı bu çalışmada 0,81 olarak hesaplanmıștır. Elde edilen bulgu uyarlama ölçeğin iç tutarlığının yüksek olduğunu göstermektedir. Ayrica 15 gün ara ile yapılan test-tekrar test bulguları ölçek maddelerinin zamana bağlı tutarlılığını göstermektedir (Büyüköztürk, 2012).

Alan dizinde yer alan diğer uyarlama çalışmalarının ölçek uyarlama adımlarını uygun bir şekilde yürütmediği görülmüştür. Biçer ve arkadaşlarının (2020) çalışmalarında ölçek uyarlaması için yeterli örneklem büyüklüğüne ulaşılmamasının yanında madde ayırt ediciliğinin incelenmesi, test-tekrar test bulguları ve ölçüt bağıntılı geçerlik sonuçları eksik kalmıştır. Diğer yandan Evren ve arkadaşlarının (2020) çalışmasında da eksik istatistiksel analizlerin yanında hesaplanan düşük katsayılar dikkat çekmektedir. Çalışmamızda ölçek uyarlama adımlarının titizlikle yürütülmesine ve bilimsel metodolojiye uygunluğuna dikkat edilmiştir.

Yapılan çalışma sonucunda, Koronavirüs Kaygı Ölçeği'nin psikometrik özelliklerinin orijinal çalışma ile paralellik gösterdiği ve Türkçe'ye uyarlamada gerekli koşulların sağlandığı bulunmuştur. Koronavirüs Kayg1 Ölçeği güvenilir ve geçerli bir ölçüm aracı olarak Türk popülasyonunda kullanılabilir olduğu görülmüştür. Ek 
olarak çalışmanın bazı sınırlılıkları bulunmaktadır. Anketler pandemi koşulları sebebiyle katılımcılara yalnız internet üzerinden yayılmış, bu nedenle örneklem internet kullanan bireyler ile sınırlı kalmıştır. Toplum içerisinde daha üst yaş grubunda bulunan ya da elverișsiz koșullara sahip olma nedeniyle internet kullanmayan bireylere ulaşılamamıștır. Bir diğer nokta kendi kendini derecelendirme ölçeklerinin tamamında söz konusu olan, katılımcıların anksiyete düzeylerinin kendi sundukları veri üzerinden değerlendiriliyor oluşudur. Katılımcılar anksiyete düzeylerini ve ilişkili soruları, içerisinde bulundukları durum ve zaman, sosyal istenirlik, kendini olduğundan iyi ya da kötü gösterme niyeti gibi yargılarla yanlı olarak cevaplamış olabilirler. Çalışmamızın veri analizi esnasında bütün cevaplar incelenerek tekrarlayıcı ve özensiz yanıtlar tespit edilmiş, veri setinden çıkarılmıştır. Ölçekte, bu tespiti kolaylaştırmak ve ölçek geçerliğini korumak amacı güden herhangi bir kontrol maddesinin bulunmayışı da bir kısıtlılıktır.

Çalışma bulgularının Türkçe alan dizine değerli bir ölçüm aracını kazandırdığı düşünülmektedir. Yaşanan pandemi sürecinde ve sonrasında yapılacak çalışmalara koronavirüse olan kaygı şiddetinin güvenilir ve geçerli ölçüm araçları ile incelenmesi araştırmacılara kolaylık sağlayacaktır. Koronavirüs ile ilgili yapılacak çalışmalarda güvenilir ve geçerli ölçüm araçlarının kullanılması önerilmektedir. Ayrıca bireylerin Koronavirüse yönelik duydukları kaygının nedenlerinin incelendiği bir çalışma da alanyazına faydalı bilgiler sunacak ve Koronavirüs pandemisinin psikolojik sonuçlarının daha iyi incelenmesine imkân tanıyacaktır.

\section{Kaynaklar}

Akbaş, G., ve Korkmaz, L. (2007). Ölçek uyarlaması (adaptasyon). Türk Psikoloji Bülteni, 15-16.

Bayram, N. (2010). Yapısal Eşitlik Modellemesine Giriş AMOS Uygulamalart. Ezgi Kitabevi.

Biçer, İ., Çakmak, C., Demir, H., ve Kurt, M. E. (2020). Koronavirüs Anksiyete Ölçeği Kısa Formu: Türkçe Geçerlik ve Güvenirlik Çalışması. Anadolu Kliniği Tip Bilimleri Dergisi, 25(Ek 1), 216-225.

Bogoch, I. I., Watts, A., Thomas-Bachli, A., Huber, C., Kraemer, M. U. G., ve Khan, K. (2020). Pneumonia of unknown aetiology in Wuhan, China: potential for international spread via commercial air travel. Journal of Travel Medicine, 27(2), 11-24.

Brown, K., ve Wang, R. C. (2020). Politics and Science: The Case of China and the Coronavirus. Asian Affairs, 1-18.

Büyüköztürk, Ș. (2012). Sosyal Bilimler İçin Veri Analizi El Kitabl. Pegem Akademi.

Ercan, İ., ve Kan, İ. (2004). Ölçeklerde geçerlik ve güvenirlik. Uludăg Üniversitesi Tip Fakültesi Dergisi, 30(3), 211-216.

Evren, C., Evren, B., Dalbudak, E., Topcu, M., ve Kutlu, N. (2020). Measuring anxiety related to COVID-19: A Turkish validation study of the Coronavirus Anxiety Scale. Death Studies, 1-7.

Guan, W., Ni, Z., Hu, Y., Liang, W., Ou, C., He, J., Liu, L., Shan, H., Lei, C., Hui, D. S. C., Du, B., Li, L., Zeng, G., Yuen, K.-Y., Chen, R., Tang, C., Wang, T., Chen, P., Xiang, J., ... Zhong, N. (2020). Clinical Characteristics of Coronavirus Disease 2019 in China. New England Journal of Medicine, 382(18), 1708-1720.

Güriş, S., ve Astar, M. (2019). Bilimsel Araştırmalarda SPSS ile Istatistik. Der Yayınları.

Hadjistavropoulos, H. D., Janzen, J. A., Kehler, M. D., Leclerc, J. A., Sharpe, D., ve Bourgault-Fagnou, M. D. (2012). Core cognitions related to health anxiety in self-reported medical and non-medical samples. Journal of Behavioral Medicine, 35(2), $167-178$

Huang, C., Wang, Y., Li, X., Ren, L., Zhao, J., Hu, Y., Zhang, L., Fan, G., Xu, J., Gu, X., Cheng, Z., Yu, T., Xia, J., Wei, Y., Wu, W., Xie, X., Yin, W., Li, H., Liu, M., ve Cao, B. (2020). Clinical features of patients infected with 2019 novel coronavirus in Wuhan, China. The Lancet, 395(10223), 497-506.

Jalloh, M. F., Li, W., Bunnell, R. E., Ethier, K. A., O'Leary, A., Hageman, K. M., Sengeh, P., Jalloh, M. B., Morgan, O., Hersey, S., Marston, B. J., Dafae, F., ve Redd, J. T. (2018). Impact of Ebola experiences and risk perceptions on mental health in
Sierra Leone, July 2015. BMJ Global Health, 3(2), 35-50. Kalaycı, Ş. (2010). SPSS Uygulamalı Çok Değişkenli İstatistik Teknikleri. Asil Yayınevi.

Lau, J. T., Griffiths, S., Choi, K. C., ve Tsui, H. Y. (2010). Avoidance behaviors and negative psychological responses in the general population in the initial stage of the $\mathrm{H} 1 \mathrm{~N} 1$ pandemic in Hong Kong. BMC Infectious Diseases, 10(1), 139-152.

Lee, S. A. (2020). Coronavirus Anxiety Scale: A brief mental health screener for COVID-19 related anxiety. Death Studies, 44(7), 393-401.

Liu, Y., Gayle, A. A., Wilder-Smith, A., ve Rocklöv, J. (2020). The reproductive number of COVID-19 is higher compared to SARS coronavirus. Journal of Travel Medicine, 27(2), 1-4.

Main, A., Zhou, Q., Ma, Y., Luecken, L. J., ve Liu, X. (2011). Relations of SARS-related stressors and coping to Chinese college students' psychological adjustment during the 2003 Beijing SARS epidemic. Journal of Counseling Psychology, 58(3), 410-423.

Meydan, C. H., ve Seşen, H. (2011). Yapısal Eşitlik Modellemesi AMOS Uygulamaları. Detay Yayıncılık.

Ren, L.-L., Wang, Y.-M., Wu, Z.-Q., Xiang, Z.-C., Guo, L., Xu, T., Jiang, Y.-Z., Xiong, Y., Li, Y.-J., Li, X.-W., Li, H., Fan, G.H., Gu, X.-Y., Xiao, Y., Gao, H., Xu, J.-Y., Yang, F., Wang, X.M., Wu, C., ve Wang, J.-W. (2020). Identification of a novel coronavirus causing severe pneumonia in human. Chinese Medical Journal, 133(9), 1015-1024.

Saadatian-Elahi, M., Facy, F., Del Signore, C., ve Vanhems, P. (2010). Perception of epidemic's related anxiety in the General French Population: a cross-sectional study in the Rhône-Alpes region. BMC Public Health, 10(1), 191-205.

Wang, W., Tang, J., ve Wei, F. (2020). Updated understanding of the outbreak of 2019 novel coronavirus $(2019-\mathrm{nCoV})$ in Wuhan, China. Journal of Medical Virology, 92(4), 441-447.

Yılmaz, Ö., ve Dirik, G. (2018). Sağlık Bilişleri Anketi (SBA)'nin Türkçe versiyonunun psikometrik özelliklerinin incelenmesi. Nesne Psikoloji Dergisi, 337-366.

Zhao, S., Lin, Q., Ran, J., Musa, S. S., Yang, G., Wang, W., Lou, Y., Gao, D., Yang, L., He, D., ve Wang, M. H. (2020). Preliminary estimation of the basic reproduction number of novel coronavirus (2019-nCoV) in China, from 2019 to 2020: A data-driven analysis in the early phase of the outbreak. International Journal of Infectious Diseases, 92, 214-217.

Zigmond, A. S., ve Snaith, R. P. (1983). The Hospital Anxiety and Depression Scale. Acta Psychiatrica Scandinavica, 67(6), 361-370. 